\title{
Effect of Problem Based Learning (PBL) on Library Usage: a Study at Faculty of Health-Care Sciences, Eastern University of Sri Lanka
}

S. Santharooban ${ }^{1}$ and T. Sathaananthan ${ }^{2}$

\begin{abstract}
Researches show that the use of library in academic institutions is decreasing due to various reasons. One of the reasons for such decrease is that the less motivation towards further reading by traditional lecture based teaching and learning. This type of teaching-learning methods entirely drives away the selfmotivated learning. Whenever the students are encouraged for the self-directed learning, the usage of library will increase and in turn, it paves the way for students to gain broader knowledge on a particular subject. In this context, Problem Based Learning (PBL) is such an approach, which encourages the selfmotivated learning. PBL is a student driven process, through which the students set the pace thus the role of the teacher becomes one of the guide, facilitator and resource person. Most of the medical schools all over the world nowadays shifted their teaching learning program to PBL. The Faculty of Health-Care Sciences (FHCS) of Eastern University of Sri Lanka (EUSL) has also adopted the PBL approach. The present study investigated how the PBL have an impact on the use of library of Faculty of Health-Care Sciences. The library usage of students was recorded during PBL sessions and other academic sessions. The data obtained were analysed statistically using chi-squared test and student-t test. The results reveal that there is an association $(p<0.05)$ between PBL session and increase in library usage and library usage significantly differs $(p<0.05$ ) between PBL session and other academic session. Further, results indicate that library usage has been increased significantly during the PBL session than other academic session.
\end{abstract}

Keywords: Chi-squared test, Library usage, Problem Based Learning, Self-directed Learning

${ }^{1}$ Corresponding author:

Assistant Librarian, Faculty of Health-Care Sciences, Eastern University of Sri Lanka, Sri Lanka. E mail: santharooban@yahoo.com

${ }^{2}$ Lecturer, Department of Medical Education and Research, Faculty of Health-Care Sciences, Eastern University of Sri Lanka, Sri Lanka. E mail: sathaananthan@yahoo.co.uk 


\section{Introduction}

It is the great tragedy for all most all academic librarians that their libraries will become a "Deserted Library" due to the decline in usage of their libraries (Carlson, 2001). A decline in use of the physical academic library is seen as an inevitable result of changes in the information landscape and in student, particularly under graduate, information-seeking habits (Applegate, 2007). Further decline in the use of physical collections and services make it difficult to justify additional space, staffing and other traditional resources (Martell, 2008). In an academic institution, the decline in the use of library will definitely affect the knowledge background of the students and staff as well. There are several reasons for the decline of the library use. Increased access to technology has altered the way that students search and use information, while the variety of electronic resources has widened the potential resource base for all students. These developments have reduced face-to-face teaching in the library and the need to visit the library building. Further less motivation by traditional lecture based learning session is another reason. Sometimes students have been provided with handful of notes and sometime, students are encouraged to use a particular text for a subject. This reduces the needs for students for further on particular subject.

In contrast to traditional lecturing method, the problem based learning (PBL) encourages the students' search for information literacy skills and thereby increase the use of library. The PBL is a learning process towards the understanding of a resolution of a problem and the problem is first encounter in the process (Schmidt, 1993). The PBL originally started in the field of Medical education and was originally introduced in the Medical School at McMaster University in Canada in the late 1960s and is now a common curriculum component in medical and health science schools around the world (Wood, 2003). During the past few decades, many medical schools have changed the traditional teaching method to problem based learning (Leung et al., 2003). This is because of its ability to foster early acquisition of cognitive skills, encourage deep learning in students, increase the self-directed learning and increasing intrinsic interest in the subject of study (Mansur 
et al., 2012). In the medicine and health sciences, PBL emphasis on real world problem solving capacity for clinical reasoning, and thus it facilitates acquisition of knowledge on both basic and clinical sciences (Barrows, 1986).

In the PBL, students are divided into group-five to eight students work collaboratively in a group, together with one or more faculty facilitators or tutors. Thereafter, problems/triggers are introduced to students by PBL tutors. Mostly the problem consist real case histories, which is the information taken by medical doctors from the patient at first instance. Problems are created/selected by the faculty to represent important priority health problems of the region as well as prototypical situations and knowledge domains (Bordage, 1987). The tutor facilitates and guides learning without contributing directly to the solution of the problem. Mostly tutor may be a teaching staff. However, librarian also acts as tutor in some universities. There are several studies on the role of librarian as a PBL tutor and most of them indicate that librarian can act as tutor for the PBL especially in first or second year of studies i.e. pre-clinical studies (Satterthwaite et al., 1995; Fyfe and Payne, 2009; Kaur and Singh, 2004; Eldredge, 2004).

After the group discussion, students will engage in self-directed study outside the tutorial. They gather the information on their learning issues at library, website, databases and/or from resource people. After a period of independent study, students return to the PBL tutorial. Students share the information they have gathered individually, teach to peers and work collaboratively to find a solution to the given problem. At the end of the discussion, they summarise what they have learned and reflect their solution to other groups, PBL tutors and experts.

After presenting the solution, the final review process will be held. An expert will review the whole session. All who participate in the process will engage in self, peer and tutor review of the PBL process and reflections on each person's contribution to that process (Barrett, 2005). This type of teaching learning process encourages the students on searching information in the library as well as via online resource. 
Studies on the effect of PBL on libraries, especially in the medical and health sciences have been gaining interest in the past years. Studies in USA, Canada, UK and even Sweden began to survey the frequency of library visits, duration of use, loans patterns, and complexity of reference questions (Kaur and Singh, 2004). Kaur and Singh, (2004) stated in their review paper that the librarians became aware of the increase in library usage and demand for information resources and they further argued that once the research on library usage showed positive relationships between PBL students compared to the students of the traditional curriculum, librarians took advantage and used this opportunity to bring forth their role as information specialist.

Rankin (1992) did a survey on library use in second-year students in four medical schools, two schools with two curricular tracks (one PBL and one conventional), one PBL school, and one conventional school. The results showed certain significant differences between PBL and conventional curriculum students and showed that PBL students were the more frequent library users, used information resources that supported the independent learning process, acquired information seeking skills at an earlier stage.

These types of studies are very useful for the library management. Rankin (1992) states that 'investigation into student use of libraries in PBL medical schools can provide useful information for the administration of the libraries either in, or changing to, the PBL curriculum. Librarians must know if program changes are needed to serve the growing number of PBL students and also if revisions are required in collection development policies.'

Faculty of Health-Care Sciences (FHCS) has introduced PBL in its curriculum. FHCS is a newly established faculty at Eastern University, Sri Lanka (EUSL). There are six departments with integrated curriculum and has both MBBS and B.Sc Nursing courses. As the faculty is located $17 \mathrm{~km}$ away from its parent organization, a separate branch library (Health-Care Library) has been established along with faculty and the library has a collection of about 5000 books and few numbers of journals and with one professional 
staff and four para-professional staff. Library serves to its users from 8.00 AM to 8.00 PM in week days and from 8.00 AM to 4.00 PM in weekends.

In FHCS, PBL is introduced in a hybrid system, where PBL is a part of curriculum. However, some medical schools like Medical School at Mc-Master University in Canada practice entire PBL system without traditional lecture based system. At FHCS, the PBL session is facilitated by tutors and resource person. Each group is assigned with a tutor. At the end of the each PBL day students are provided with learning needs related to the case history. Students search the information to study the learning needs given in the PBL class. In the next PBL day the learning needs will be discussed. This will continue for a week. This week is called PBL week. During this PBL week, there will not be other academic programs for the particular batch of students. Other academic (non-PBL) activities include lecturing, small group discussion, large group discussion, group activities, demonstration, practical etc. During PBL week, students fully engaged in self study and discussion. The timetable is also set in such a way to facilitate the PBL.

The objective of the present study is to investigate the library usage of medical students at Faculty Health-Care Sciences during the PBL sessions and to compare this usage during other academic sessions. This study looked at the number of students visited the library, number of students borrowed books, and number students did the studied within the library during both PBL session and other academic sessions.

\section{Methodology}

Studies were carried out using the usage statistics of health-care library from November 2008 to July 2010 and records of PBL weeks (dates) for second batch of medical students during the above period was obtained from the faculty time table. Usage statistics consist the library usage which includes number of students visited library, number of students borrowed books, and number of students did the in-house reference. As there are no library automation system in the health-care library, usage statistics was recorded manually by library staff. 
The library usage during the PBL weeks and preceding academic (non-PBL) weeks were compared using student-t test at $95 \%$ confident interval for significant difference. Further, association between PBL period and increased frequency of library usage was tested by chi-squared test. All the statistical analysis was performed in Minitab v.14 statistical software.

\section{Results and Discussion}

Before analyzing the results it was confirmed that there were no two PBL session same time for two different batches of students. For the purpose of this study, PBL session time table for second batch was obtained. There were seven PBL weeks during study period for that particular batch and these seven PBL weeks were compared with preceding non-PBL week.

The chi-squared test revealed that there is an association $(p<0.05)$ between PBL session and the increase in library usage. Therefore it confirms that PBL session has impact on the library usage.

Results of student-t test revealed that there were significant differences $(p<0.05)$ in library usage between PBL weeks and other academic weeks. This result is similar to the results obtained in Rankin (1992) studies. Average students visited per day during PBL weeks (35 \pm 2.9$)$ was higher than the average students visited per day during preceding non-PBL weeks (25.7 \pm 2.5$)$.

This difference in library usage can be shown in the graphs (Fig $1 \& 2$ ). The figure 1 shows the average usage by students per day and is expressed in terms of number of students. In most of the PBL weeks, average students' usage is higher than the preceding non-PBL week. The figure 2 shows the daily variation of students' usage. Zero usages were indicated alternatively in the same graph. This is because when there is PBL week for a batch, there will not be lectures in that week for the particular batch. 
This result clearly shows that students use the library more frequently during the PBL weeks when comparing with non-PBL weeks. In general, most of the medical students use their own books, as it is their custom to have their own learning aids such as books, parts of skeleton etc. They are coming to the library to borrow the books instead of studying within library. However, the present study reveals sudden increase in library usage, particularly in in-house reference during PBL weeks. This type of library usage improve the students' self learning ability, lifelong learning and information searching particularly in medical profession, where continuous learning essential to overcome newly emerging problems. It has been noted during PBL weeks, because increased users for in-house reference simultaneously, problem on space and seating arrangements arise in the library. Sometime students are forced to read while standing.

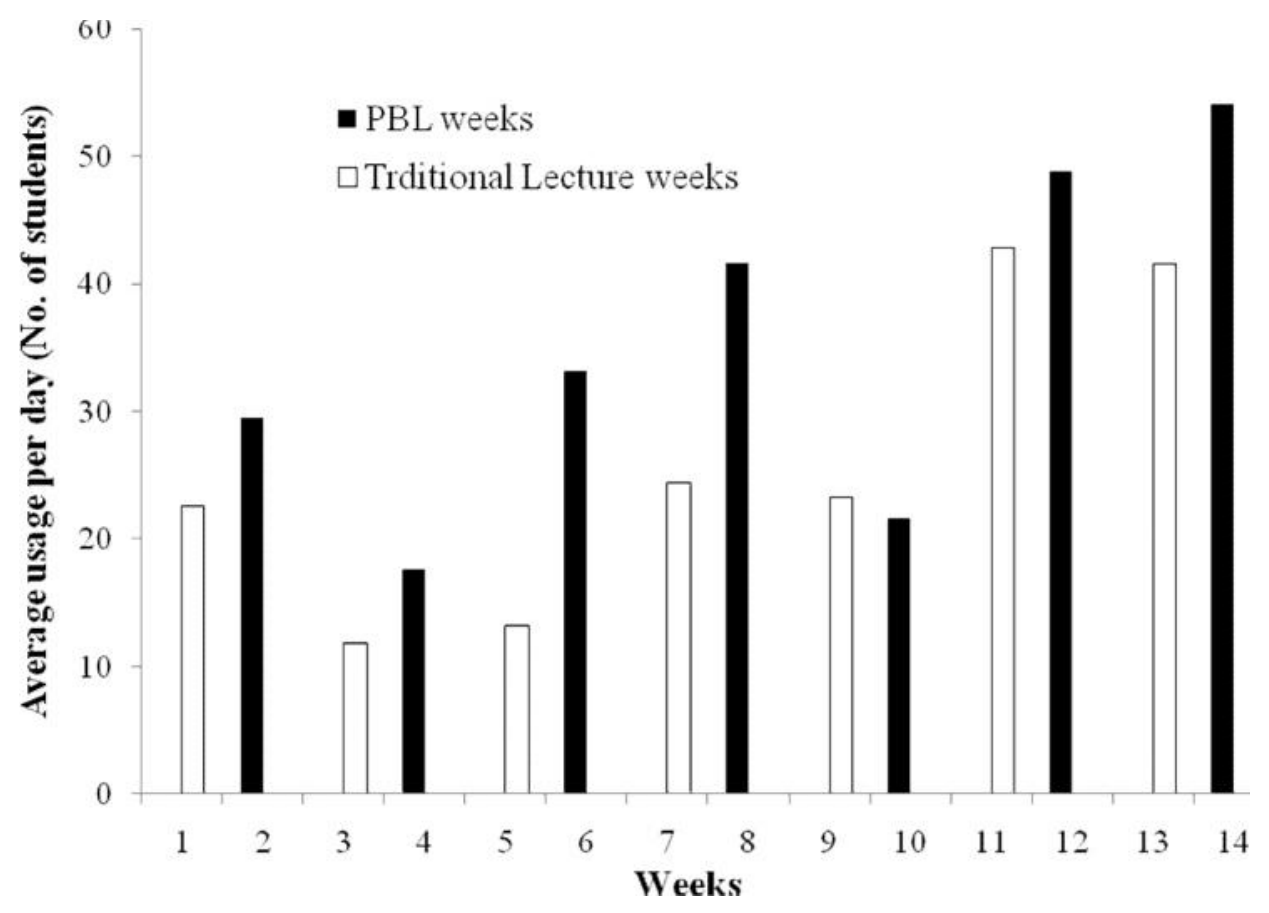


Figure 1: Comparison of average library usage during PBL week and preceeding non-PBL week

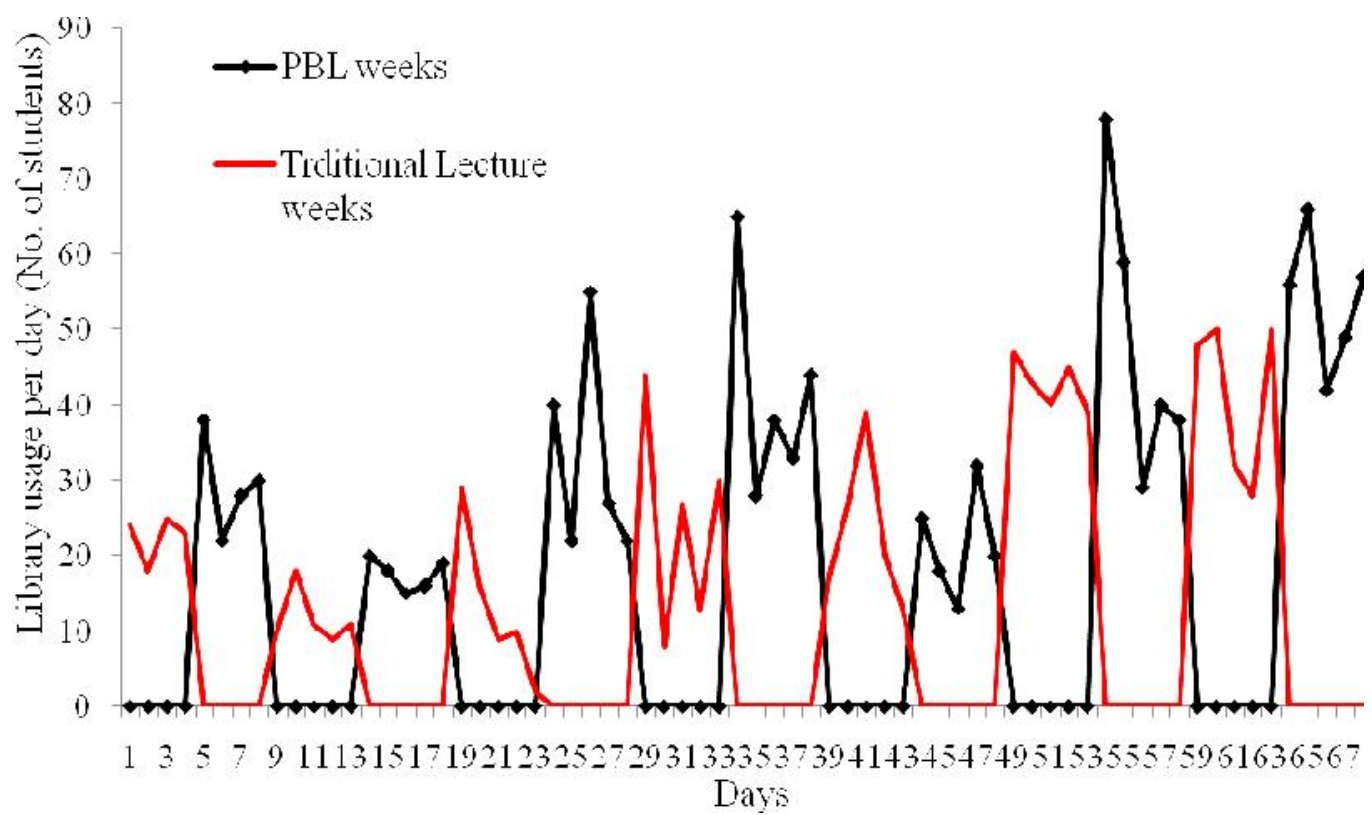

Figure 2: Daily library usage during PBL week and preceding non-PBL week

Even though, there is an increased library usage during PBL session, their information seeking behavior is not much improved. Observation during the study period reveals that in both situations they rely mostly on the text books than other reference materials. Sometime, during PBL session, PBL tutors suggest some text books for further reading. Due to this most of the students tries to study a same book than browsing other reference books and journals. In order to improve their information seeking skills, students should be trained in information literacy. Especially information literacy is very vital for Problem Based Learning for it successful achievement.

As the self-directed learning is the heart of the PBL, information literacy is important to PBL. Many authors argued that information skills (Rankin, 1999) or information literacy competencies (Cunningham \& Lanning, 2002) are essential to the learning process in PBL environment. Oker-Blom (1998) stated that students are being challenged to acquire 
sophisticated information-seeking skills in the PBL. The American Library Association (ALA, 2000) stated that "to take fullest advantage of problem-based learning, students must often use thinking skills requiring them to become skilled users of information sources in many locations and formats, thereby increasing their responsibility for their own learning." Further, information literacy introduces different information sources, and new possibilities for information gathering and as a whole improve the information seeking skills which are very essential for the PBL.

\section{Conclusion}

As the Library is the heart of an academic institution, library use is pivotal for effective learning. However, presently university students rarely use the library and its resources and many students use the library as a reading room not as an information centre. In the traditional lecture based learning, the motivation for self learning is limited and the students are driven to use limited resources such as few text books and their handouts. However, the PBL increases the self motivation for learning and it changes the library use. According to the present study, the PBL has impact on the library and increase the library usage than other academic activities. Increase in library use will definitely increases the knowledge on their particular subject. The PBL further assist the students to be lifelong learner. Especially for the medical field, lifelong learning is must to aware the latest development in their field and to face the information explosion, which is more pressing than in other fields. Though the PBL is widely practiced in medical education, it can be recommended to other non-medical faculties to adopt PBL in their curriculum. The present study considered library usage only in terms of number of students. However, further studies in this aspect should consider variety and types of resources that student prefers and students information seeking behaviour during PBL and non-PBL situations. Moreover, students should be trained in information skills, which will support the students in obtaining information quickly and the library facilities should be improved further to support increased in-house reference during PBL session. 


\section{References}

ALA. (2000). Information Literacy Competency Standards for Higher Education. American Library Association. Retrieved from: URL:http://www.ala.org/acrl/standards /informationliteracycompetency (Accessed on 02-05-2013).

Applegate, R. (2007). Whose decline? Which Academic Libraries are "Deserted" in Terms of Reference Transactions?. Reference \& User Services Quarterly, 48(2), 176-189.

Barrett, T. (2005). Understanding problem -based learning. In, Barrett, T., Mac Labhrainn, I., Fallon, H. (Eds). Handbook of Enquiry \& Problem Based Learning. Released under Creative Commons licence. Retrieved from:

http://www.nuigalway.ie/celt/pblbook (Accessed on 02-05-2013).

Barrows, H. S. (1986). A taxonomy of problem-based learning methods. Medical Education, 6( 20),481-486.

Bordage, G. (1994). Elaborated Knowledge: A key to successful diagnostic thinking. Academic Medicine, 69 (11), $883-885$.

Carlson, S. (2001).The Deserted Library: As Students Work Online, Reading Rooms Empty Leading Some Campuses to Add Starbucks, "Chronicle of Higher Education. Retrieved from: http://chronicle.com/article/As-Students-Work-Online/32747 (Accessed on 0404-2013).

Cunningham, T.H. and Lanning, S. (2002). New frontier guides: faculty-librarian collaboration on information literacy. Reference Services Review,30(4), 343-348.

Eldredge, J.D. (2004). The librarian as tutor/facilitator in a problem-based learning (PBL) curriculum. Reference Services Review, 32 (1), 54 - 59.

Fyfe, T.M and Payne, G.W. (2009). Undergraduate medical education: Redefining the role of the librarian. Paper presented at the meeting Positioning the Profession: the Tenth International Congress on Medical Librarianship (ICML), Brisbane, Australia. Retrieved from: http://espace.library.uq.edu.au/eserv/UQ:179933/n7 6 Fri Fyfe 174.pdf (Accessed on 04-04-2013). 
Kaur, K and Singh, G. (2004). Emerging roles for the Librarian in Problem Based Learning. Journal of Problem-Based Learning, 2004, 2 (2). Retrieved from : eprints.rclis.org/8231/1/TrendsPBL_for_journal.pdf (Accessed on: 5-10-2010).

Leung, K.H., Lue, B.H., and Lee, M.B (2003). Development of a teaching style inventory for tutor evaluation in problem-based learning. Medical Education, 37(5), 410-416.

Mansur, D.I., Kayastha, S.R., Makaju, R, and Dongol, M. (2012). Problem Based Learning in Medical Education. Kathmandu University Medical Journal,10 (4), 78-82.

Martell, C. (2008). The absent user: Physical use of academic library collection and service continues to decline 1995-2006. The journal of academic librarianship, 34 (5), 400-407.

Oker-Blom, T. (1998). Integration of Information Skills in Problem Based Curricula, 64th IFLA General Conference, August 16-21, 1998, Amsterdam.

Rankin, J.A. (1992). Problems based medical education: effect on library use. Bull Med Libr Assoc, 80 (1).

Rankin, J.A. (Ed.).(1999). Handbook on problem-based learning. New York, NY: Medical Library Association and Forbes Custom Publishing.

Satterthwaite, R.K., Helms, M.E., Van Antwerp, M. and Woelfl, N.N. (1995). Library faculty role in problem-based learning: facilitating small groups. Bull Med Libr.Assoc, 83 (4), 465-468.

Schmidt, H.G. (1993). Foundations of problem-based learning: some explanatory notes. Medical Education, 27, $422-432$.

Wood, D.F. (2003). ABC of learning and teaching in medicine Problem based learning. British Medical Journal; 326 (7384),328-330. 